\title{
MULTIPLICITY AND DEVELOPMENT OF ACHIEVEMENT MOTIVATION: A COMPARATIVE STUDY BETWEEN GERMAN ELITE ATHLETES WITH AND WITHOUT A DISABILITY
}

\author{
Astrid Kämpfe* \\ University of Paderborn, Germany \\ Oliver Höner, \\ University of Tübingen, Germany \\ Klaus Willimezik \\ Technical University of Darmstadt, Germany
}

\begin{abstract}
*Corresponding author: Astrid Kämpfe, Department of Sport and Health, University of Paderborn, Warburger Strasse 100, 33098 Paderborn, Germany. E-mail: astrid.kaempfe@upb.de, Phone +49 5251 601868, Fax +495251601870
\end{abstract}

While achievement motivation influences success in elite sports, the empirical knowledge on its manifold aspects and its development is quite rudimentary, especially in disability sports. This study analyzes motivation of athletes with a disability $(\mathrm{N}=73)$ as opposed to athletes without a disability $(\mathrm{N}=156)$. We surveyed these German elite athletes $(\mathrm{N}=229)$ in a $2 \times 3$ design retrospectively, regarding various facets of achievement motivation during three career phases (initiation, development and mastery). Results showed that enjoying the sport and improving one's personal performance level have great relevance for athletes with a disability, whereas incentives such as career opportunities and earning money are less important. MANOVAs revealed differences between athletes with and without a disability regarding incentives as well as personal factors. For the latter, nearly all personal factors developed significantly over the career phases. These results provide empirical knowledge for new implications regarding psychological consultations in elite disability sports.

Keywords: sport and exercise psychology, elite disability sport, motives, incentives, career phases

\section{INTRODUCTION}

Elite disability sports have gained considerable social as well as political relevance in the last several years. In some ways, this recent attention seems to converge with the elite sports of athletes without a disability. Beginning with the 1988 Summer Olympic Games in Seoul and the 1992 Winter Olympic Games in Albertville, the Paralympic Games have been held in the same cities and used the same venues immediately following the Olympic Games. Furthermore, a degree of professionalism can be observed, which, in some cases, is reminiscent of the elite sports of athletes without a disability. Meanwhile, there are athletes with disabilities who make their living, at least in part, as professionals.
From a sport psychology perspective, a common factor between elite athletes with and without a disability can be found in the fact that achievement motivation serves as a core factor for a successful career in sports. Elite athletes must exhibit an extremely high level of long-term achievement motivation to handle the inordinate time commitment required for competing at the highest levels of athleticism (Ericsson, Krampe \& Tesch-Römer, 1993). Additionally, elite athletes must demonstrate intense determination and exert incredible physical effort during competitions, and they must be able to cope with failure as well as success. Over the course of an athlete's career, the athlete is repeatedly confronted with various barriers that require extreme internal motivational resources to overcome.

This extreme degree of achievement motivation in elite athletes gives rise to a number of unanswered scientific questions that result from the complexities of the field. When examining the 
current research regarding achievement motivation in the context of a sports career in general and when considering the careers of athletes with a disability in particular, a deficit can be observed from at least three different perspectives. First, the lack of studies concerning the complex diversity of achievement motivation must be acknowledged. Although there are a number of studies on athletic achievement motivation, the majority of them are monotheoretical, focusing on a single dimension or facet within this complex construct (e.g., Duda, 2007; Feltz \& Lirgg, 2001). Second, the development of the motivational facets during the course of a sports career is rarely included in empirical analyses. As it is assumed that sports careers consist of different developmental phases (Côté, Baker \& Abernethy, 2003; Salmela, 1994; Wylleman \& Reints, 2010), it appears mandatory to contemplate sports-related achievement motivation from a phase-specific perspective and to incorporate various aspects of development into the analyses. Hereby, practical knowledge concerning the field of talent scouting as well as talent development can be gathered. Third, there is a general lack of psychological studies involving elite athletes from disability sports with respect to the course of their careers, career management and psychosocial effects. "In comparison, relatively few researchers have examined the psychological dynamics of disability sports" (Martin, 2008, p. 275). Especially when comparing the findings to elite sports of athletes without a disability, a lack of empirical knowledge must be acknowledged. Generally, the studies investigate a certain motivational facet among a specific group of athletes with a disability, for example, wheelchair athletes (Martin, 2002, 2008; Martin, AdamsMushett \& Smith, 1995; Skordilis, Koutsouki, Asonitou, Evans, Jensen \& Wall, 2001). This lack of empirical evidence becomes more profound when considering that the general barriers previously mentioned may be even more intense and complex for athletes with a disability. With respect to the ongoing tendency for professionalism in this field, one may assume that extrinsic incentives have gained relevance for these athletes.

The study presented in this paper aims at reducing these deficits and focuses on the multiplicity of achievement motivation in the setting of disability sports of German elite athletes in different developmental phases.

\section{Multiplicity of achievement motivation}

Within his action-theoretical perspective, Nitsch (1985) understands action - as an intentional organization of behavior in a situational context - to be the key concept. Following Nitsch's perspective, the present survey considers an individual's motivation as a current psychological state that results from the interaction of personal factors and situational conditions. The differentiation into personal and situational incentives has a long tradition within the psychology of motivation, which can be traced back to Lewin (1936) and Murray (1938).

The consideration of achievement motivation within a person-situation context can be embedded into a developmental psychological perspective. To classify a sports career into different phases, a developmental model of Salmela (1994) was modified by Kämpfe (2009) to analyze the development of achievement motivation. During the initiation phase, the athlete gradually becomes familiar with a specific sport and, little by little, a regularity of practice develops. The following phase, development, usually occurs during adolescence and is characterized by an intensive, achievement-oriented exercise process as well as by frequent competition. Finally, the mastery phase is reached and the athlete's lifestyle is completely focused on the sport as the athlete now competes on a national or international level (for a similar developmental framework, see Côté, Baker \& Abernethy, 2003). With regard to the lifespan theory in developmental psychology, the personality is considered to be a complex and multidimensional construct (Baltes, Lindenberger \& Staudinger, 2006), and the theoretical propositions of multidimensionality refer to different aspects of the personality as well as to different dimensions within achievement motivation itself. The dimensions of the athletic achievement motive are reflected in different facets that focus on success and failure (hope 
for success vs. fear of failure), on the reference norm (task orientation vs. ego orientation), on competence (self-efficacy) or on the evaluation of incentives (intrinsic vs. extrinsic motivational incentives). Consequently, the achievement motivation may develop multi-directionally (Baltes et al., 2006), and, therefore, the different facets described in the following paragraphs must be considered within the construct of a complex perspective.

\section{Current state of research}

Considering the early publications of McClelland (1953) and Atkinson (1957), the classical facets are the dispositions known as hope for success and fear offailure. According to Atkinson's risk-takingmodel, the evaluation of the success incentive as well as the probability of success formed through theses dispositions have a relevant impact on the choice of tasks (for an overview see Brunstein \& Heckhausen, 2008). Individuals who are confident about their success focus their cognitions and emotions on success. They usually pursue realistic goals, are able to delay rewards for a longer period of time and show greater endurance during action, especially when dealing with unexpected barriers. Further on, they seek information about their individual competences and by attributing success to internal factors and failure to external factors, they employ self-serving attributions. Therefore, success displays a more significant positive incentive than the negative incentive that accompanies failure. Individuals with fear of failure also want to be successful; however, their cognitions and emotions are predominantly focused on prevention of failure. For them, failure has a greater negative incentive than the positive incentive that accompanies success. Therefore, the manifestation of success and failure motivation decisively influences the choice of tasks with respect to the degree of difficulty. With respect to disability sports, no empirical evidence was found concerning these aspects.

Another facet (dimension) of achievement motivation (independent of hope for success and fear of failure) emphasizes the subjective relevant reference norm for the demonstration of competence within achievement situations. Nicholls (1984) and Duda (1992) differentiate in their goal perspective approach between task and ego orientation. While task orientation focuses on mastering a specific task (individual reference norm), ego orientation or competitiveness aims at outperforming another person. Biddle, Wang, Kavassanu and Spray (2003) offer a systematic review on goal orientations that includes 98 empirical studies and 20.000 test subjects. Their study shows correlations between the two dimensions as well as other aspects such as the perception of one's own competence, causal attribution or aggression in sports. With regard to disability sports, White and Duda (1993) used the Task and Ego Orientation in Sport Questionnaire (TEOSQ; Duda, 1992) and analyzed the two dimensions with respect to athlete's beliefs about athletic success. While task orientation was associated with belief that success is the result of exercise, effort and external factors, ego orientation was connected to belief that success is regulated by ability, luck and illegal benefits. Skordilis et al. (2001) used the TEOSQ to analyze the motivational orientations of American basketball and marathon wheelchair athletes at the national level. While there was no gender-specific difference when comparing these two sports, a stronger ego orientation was found among marathon athletes. However, when analyzing task orientation, there was no difference between basketball and marathon athletes. Skordilis et al. also employed the Sport Orientation Questionnaire (SOQ; Gill \& Deeter, 1988) and found that goal orientation is equivalent to task orientation within the TEOSQ and that competitiveness corresponds to ego orientation. Furthermore, a third dimension called win orientation is also assessed using the SOQ. According to this study, male athletes demonstrate higher levels of competitiveness, while female athletes demonstrate stronger goal orientation. Concerning the win orientation, no gender-specific difference could be found. When comparing the two sports, a stronger win orientation could be ascertained in basketball players, while marathon athletes possessed stronger goal orientation. With respect to the 
degree of competitiveness, no difference was found between the two sports. In a similar manner, Martin et al. (1995) analyzed the orientations of swimmers with a disability and found that while they possessed a strong competitiveness and goal orientation, their win orientation was merely at a moderate level.

A subjective criterion of competence in the context of achievement motivation is generated through self-efficacy, which addresses the perception of one's individual premise to accomplish a certain task or activity (Bandura, 1997). Numerous studies certify a great predictive power within a health-related setting (e.g., Desharnais, Boullion \& Godin, 1986; Dzewaltowski, Noble \& Shaw, 1990). Within the context of sports, the meta-analyses of Moritz, Feltz, Fahrbach and Mack (2000) present significant correlations between self-efficacy and athletic performance, emphasizing that selfefficacy may be the cause as well as the result of achievement. Martin (2002; 2008) focuses extensively on self-efficacy of wheelchair athletes. For a sample of basketball players, he was able to prove that elite athletes demonstrate stronger self-efficacy regarding practice sessions as well as more negative emotions than people who engage in sports at a leisure level. Both aspects can be explained by the great amplitudes of practice in elite sports (Martin, 2008, p. 283). For marathon athletes, Martin (2002) found a positive correlation between self-efficacy and positive emotions, which seem to have great relevance for achievement.

With respect to the evaluation of incentives, the focus on incentives in the sense of a personal disposition must be regarded. The two dimensions, activity-related motivation and purpose-related motivation, are derived from the extended cognitive model of motivation. They come into effect at different stages of action, and they take into account the intrinsic and extrinsic focus of an individual (Rheinberg, 2008). However, the valence within achievement motivation is displayed by external, motivational incentives. Numerous studies have analyzed these situational components in the context of leisure sports as well as in the context of exercise and fitness (e.g., Ashford, Biddle \& Goudas, 1993; Frick \& Prinz, 2007). In the context of German elite sports, Kämpfe (2009) found that intrinsic motivation decreases during the course of an elite athlete's career. That is predominantly caused by increasing lack of enjoyment. Meanwhile, extrinsic motivation gains relevance, which can mainly be ascribed to the increased existence and importance of financial incentives. Comparable studies for the setting of disability sports are not, as yet, available.

\section{Problem statements}

To address the deficits of empirical evidence as mentioned in the beginning of the paper and confirmed by the current state of research presented herein, we conducted a survey of German elite athletes. It considers the complexity and multidimensionality of achievement motivation. We analyzed different personal factors as well as situational incentives from a developmental perspective during the course of athletes' careers. Achievement motivation of athletes with a disability compared to the motivation of athletes without a disability was the focal point of this research. In detail, we assessed the following research questions:

1. What are the main incentives of the motivational spectrum in disability sports?

2. Are there any differences between elite athletes with and without a disability with respect to their achievement motivation (personal factors, motivational incentives) in their current phase of mastery?

3. How do personal factors of elite athletes with a disability in contrast to personal factors of athletes without a disability develop during the course of their sports career (initiation, development and mastery phase)?

\section{METHODS}

\section{Sample}

The study surveyed 229 elite German athletes who were split into two subsamples. Table 1 shows the different characteristics of elite athletes with and without a disability. 
Kämpfe, Höner et al.

Table 1. Sample characteristics

\begin{tabular}{|c|c|c|}
\hline Demographic data & $\begin{array}{l}\text { Athletes with a disability } \\
\qquad(N=73)\end{array}$ & $\begin{array}{l}\text { Athletes without a disability } \\
\qquad(\mathrm{N}=156)\end{array}$ \\
\hline Gender & $\mathrm{N}=30$ (f); $\mathrm{N}=43(\mathrm{~m})$ & $\mathrm{N}=88(\mathrm{f}) ; \mathrm{N}=68(\mathrm{~m})$ \\
\hline $\operatorname{Age}(\mathrm{M} \pm \mathrm{SD})$ & $27.27 \pm 8.01$ & $23.97 \pm 4.01$ \\
\hline \multicolumn{3}{|c|}{ Category of sport (\%) } \\
\hline Team & 53.4 & 62.2 \\
\hline Individual & 46.6 & 37.8 \\
\hline \multicolumn{3}{|c|}{ Level of performance $(\%)$} \\
\hline A-squad & 71.2 & 44.2 \\
\hline B-squad & 9.1 & 22.0 \\
\hline C-squad & 4.5 & 3.9 \\
\hline First national league & 15.2 & 29.9 \\
\hline \multicolumn{3}{|l|}{ Status (\%) } \\
\hline Amateur & 75.0 & 35.1 \\
\hline Semiprofessional & 19.4 & 37.6 \\
\hline Professional & 5.6 & 27.3 \\
\hline \multicolumn{3}{|c|}{ Career phase (years; $\mathrm{M} \pm \mathrm{SD}$ ) } \\
\hline \multicolumn{3}{|l|}{ Initiation } \\
\hline Development & $15.80 \pm 6.03$ to $20.44 \pm 6.59$ & $1289+2.68$ to $1759+250$ \\
\hline Mastery & Since $20.25 \pm 6.21$ & Since $17.86 \pm 2.32$ \\
\hline \multicolumn{3}{|c|}{$\begin{array}{l}\text { Amplitude of practice } \\
\text { (hours per week; M } \pm \mathrm{SD} \text { ) }\end{array}$} \\
\hline Initiation & $3.35 \pm 1.84$ & $4.88 \pm 2.91$ \\
\hline Development & $5.84 \pm 2.80$ & $10.01 \pm 4.44$ \\
\hline Mastery & $9.56 \pm 4.68$ & $16.01 \pm 6.47$ \\
\hline
\end{tabular}

a A-squad, B-squad and C-squad are subject to the federal level in Germany. Members of the A-squad can be classified as "all-state first team athletes"; members of the B-squad can be classified as "all-state second team athletes". Members of the C-squad are junior athletes with positive prospects to eventually proceed to the B- and A-squad.

Among the athletes with a disability $(\mathrm{N}=73), 36$ athletes had a physical impairment and were engaging in basketball, table tennis, swimming or fencing, while 37 athletes had a sensory impairment and were participating in goal ball, judo, soccer, handball, table tennis, basketball, track and field, swimming, tennis, badminton, water polo or skiing. Additionally, 42 athletes had a congenital disability, while 29 athletes acquired their disability later in life.
From the latter, nine athletes were engaged in competitive sports before they sustained their disability, ten people were engaged in leisure sports activities and ten athletes were not engaged in sports at all prior to their disability.

Majority of athletes surveyed were members of the national A-squad, B-squad or the first national league in Germany. Comparing the two subsamples of athletes with and without a disability, significant differences concerning age 
$(\mathrm{t}=-3.30 ; \mathrm{df}=88.91 ; \mathrm{p} \leq .001)$, gender $(\mathrm{c} 2=4.67$; $\mathrm{df}=1 ; \mathrm{p}=.034)$ and level of performance (c2 = $36.41 ; \mathrm{df}=6 ; \mathrm{p} \leq .001$ ) became evident. In order to analyze the relevance of these differences, subsamples were matched in terms of gender and level of performance, what led to a significant reduction of the sample size $(\mathrm{N}=140)$. Age could not be taken into account within the matching process due to even greater loss of participants. Since evenly matched subsamples showed analogous results when compared to the original subsamples, the latter were kept and subject to further analyses reported in this paper. Nevertheless, the variables of age and gender were considered as covariates.

\section{Procedures}

The study design was reviewed by three Institutional Review Boards (National Institute of Sport Science in Germany, German Olympic Sport Federation, National Paralympic Committee of Germany). The nature of the study was explained to all participants and they indicated their consent by returning the survey.

To recruit athletes with and without a disability and to ensure a high response rate, different federations or national and regional coaches were contacted and asked for their support. Whenever possible, a member of the research group distributed a paper-pencil version of the questionnaire, e.g. during training camps. In some cases, team managers were asked to hand out und collect the questionnaires. Due to economic reasons, some of the athletes with a disability received the questionnaire as an MSWORD document that could be accessed and answered using a computer and returned via email. The time required to complete the survey was approximately 30-40 minutes.

The $2 \times 3$ study design considered two subsamples (elite athletes with or without a disability) as well as three career phases (initiation, development and mastery) as independent variables. To assess these developmental phases, the survey had a retrospective character. The research participants had to complete all scales initially from their current perspective as an elite athlete. Furthermore, the participants were asked to reflect on earlier phases of their athletic career and to answer all personal disposition scales retrospectively from the perspective of their initiation and development phase. Evaluation of situational incentives was only collected for the current phase of mastery because the method turned out to be very time consuming and, in some cases, complicated, especially for those athletes with a disability (cf. dependent measures).

\section{Dependent measures}

The different facets of achievement motivation of German elite athletes were measured using validated German scales, some of them underlying Anglophone scales. All scales were complemented by a short introduction to encourage the athletes to refer all statements to their individual athletic situation. The classical dimensions of achievement motivation (hope for success and fear of failure) were assessed via the Achievement Motives Scale (AMS) (Wenhold, Elbe \& Beckmann, 2008). The task and ego orientation of the athletes were measured using the German version of the Task and Ego Orientation in Sports Questionnaire (TEOSQ-D) (Rethorst \& Wehrmann, 1998). Data concerning athletes' self-efficacy were collected using the Selfefficacy for Sports Activities Scale (SSA-Scale) (Fuchs \& Schwarzer, 1994). Activity-oriented motivation and purpose-oriented motivation were measured via the Incentive Focus Scale (AF-Scale) (Rheinberg, 1989). Except for the AF-Scale, which was based on a six-point scale, all items were assessed using a four-point Likert scale. After a pretest involving 58 athletes, the SSA-Scale and the AF-Scale were abbreviated for the purpose of test economy. Reliability of the scales demonstrated a satisfactory or good internal consistency of all scales in all career phases $(\alpha=.70-.90)$ except for the activity- and purpose-related motivation in both retrospective phases $(\alpha=.64-.69$; for more details regarding the reliability of the scales see Table 3 ).

For the data to ascertain motivational incentives, we used three different methods. To compare athletes with and without a disability, 
we employed an incentive-ranking method, as athletes without a disability were surveyed earlier using this method. The incentives, which were derived from qualitative interviews (Willimczik \& Kronsbein, 2005), were presented to the participants on individual pieces of paper (see measure 1 in Table 2). The participants were then asked to sort them according to their motivational relevance by assigning ten points to the most relevant incentive and one point to the least relevant incentive. To validate the ranking method and to obtain a more detailed analysis of the situational incentives, we applied two more methods within the group of athletes with a disability. First, participants had to evaluate ten different incentives on a six-point Likert-scale (see measure 2 in Table 2), and second, they were asked to respond to an open-ended question about the three dominant incentives for engaging in disability sports. The latter method was the first to be completed within the questionnaire to avoid results bias due to the incentives presented within the other methods.

\section{Statistical Analysis}

Data were processed using the PASW (Predictive Analysis SoftWare; version 18). The first problem statement was addressed using descriptive statistics. For the second problem statement, MANOVAs were conducted separately to analyze group differences concerning the personal factors and situational incentives. Whenever the assumption of sphericity was violated, a correction of the degree of freedom according to Greenhouse-Geisser was carried out. In terms of follow-up tests, additional ANOVAs were assessed for every single motivational facet. For the third problem statement, $2 \times 3$ repeated measures ANOVAs were computed (including the group and developmental factors). All tests analyzing group differences were controlled for age and gender.

Significant results (significance level $\mathrm{p} \leq .05)$ were complemented by the effect size Eta2 to estimate the practical relevance of results. According to Cohen (1988), an effect of $\eta 2=.01$ must be regarded as small, $\eta 2=.06$ represents a medium effect and when $\eta 2=.14$ or above, we have large effects.

Table 3. Personal factors and situational incentives in the course of a career $(M \pm S)$ and multi-and univariate results of group differences between athletes with and without a disability in the mastery phase (controlled for gender and age)

\begin{tabular}{|c|c|c|c|}
\hline \multicolumn{2}{|c|}{$\begin{array}{l}\text { Measure } 1 \text { : Incentive ranking method }{ }^{\text {a }} \\
(\mathrm{N}=68 ; 1 \text { = unimportant; } 10=\text { very important) }\end{array}$} & \multicolumn{2}{|l|}{$\begin{array}{l}\text { Measure 2: Likert-based evaluation of incentives a } \\
(\mathrm{N}=71 ; 0=\text { not important at all; } 5=\text { very important) }\end{array}$} \\
\hline Enjoying the sport & $7.79 \pm 2.65$ & Enjoying the sport & $4.56 \pm 0.83$ \\
\hline Improving one's performance level & $7.29 \pm 2.35$ & Improving one's performance level & $4.50 \pm 0.79$ \\
\hline Competing with others & $6.04 \pm 2.53$ & Gaining approval & $3.97 \pm 1.07$ \\
\hline Gaining approval & $6.01 \pm 2.49$ & Proving that athletes with a disability can just as well achieve maximum performances & $3.83 \pm 1.44$ \\
\hline Leading an active lifestyle & $5.86 \pm 2.51$ & Increasing the acceptance of people with disabilities within society & $3.81 \pm 1.51$ \\
\hline Increasing self-consciousness & $5.72 \pm 2.34$ & Competing with the achievements of athletes without disability & $2.93 \pm 1.87$ \\
\hline Having social contact & $5.64 \pm 2.69$ & Increasing one's own acceptance of the disability & $2.76 \pm 1.86$ \\
\hline Having career opportunities & $3.88 \pm 2.49$ & Compensating for one's disability & $2.74 \pm 1.62$ \\
\hline Traveling around the world & $3.84 \pm 2.34$ & Traveling around the world & $2.73 \pm 1.41$ \\
\hline \multirow[t]{2}{*}{ Earning money } & $3.04 \pm 2.60$ & Financial and material incentives & $2.24 \pm 1.74$ \\
\hline & & Experiencing a new sense of life after sustaining the disability & $2.00 \pm 2.10$ \\
\hline
\end{tabular}

Note. The dotted lines indicate the grouping of the variables mentioned in the text.

${ }^{a}$ Further explanations of both measures can be retrieved from the text.

\section{RESULTS}

\section{Motivational incentives in elite disability sports in the phase of mastery (question 1)}

Analysis of the ranking method allowed for classification of situational incentives into three groups (Table 2, left). Thus, "enjoying the sport" and "improving one's performance level" were the most relevant incentives among athletes with a disability. The incentives "competing with others", "gaining approval", "leading an active lifestyle", "increasing self-consciousness" and 
"having social contact" were considered to have a medium motivational relevance. "Having career opportunities", "traveling around the world" and "earning money" were only subordinately important.

The results from the ranking method can be widely confirmed by the results from the Likertbased analysis of incentives. However, based on their relevance, four groups of incentives were identified (Table 2, right). Again, "enjoying the sport" and "improving one's performance level" were the most motivating incentives. The second group of incentives was characterized by social references ("gaining approval", "proving that athletes with a disability can just as well achieve maximum performances", "increasing the acceptance of people with a disability within society"). Less essential, but still of medium relevance, were the incentives "competing with athletes without a disability", "increasing the personal acceptance of one's disability", "compensating for one's disability" and "traveling around the world". "Financial and material incentives" as well as "experiencing a new sense of life after sustaining the disability" were less important to these athletes.

The third method asked open-ended questions about the three most important incentives for engaging in their sport. "Team spirit" $(n=25)$ and "enjoying the sport" $(\mathrm{n}=24)$ were mentioned most frequently, followed by "success" $(\mathrm{n}=18)$, "physical fitness" $(\mathrm{n}=14)$, "social contacts" ( $\mathrm{n}=13)$, "dynamics of the sport" $(\mathrm{n}=8)$ and "traveling" $(\mathrm{n}=8)$. Many other incentives were mentioned rarely $(\mathrm{n} \leq 5)$, while material incentives such as "career" and "money" were not mentioned at all by elite athletes with a disability.

\section{Personal factors and situational incentives of athletes with and without a disability in the current phase of mastery (question 2)}

For the current phase of mastery, results displayed several differences between athletes with and without a disability. The multivariate analysis of seven personal factors (Figure 1, top and Table 3) showed a significant group difference, displaying a medium effect (F7, $209=2.56$; $\mathrm{p}=.015 ; \eta 2=.08)$. According to the follow-up tests, the difference predominantly resulted from athletes with a disability showing a significantly stronger task orientation as well as (marginally significant) lower ego orientation and perceived self-efficacy. The effect size of this finding turned out to be rather small $(\eta 2=.03, \eta 2=.01$, $\eta 2=.01$, respectively).

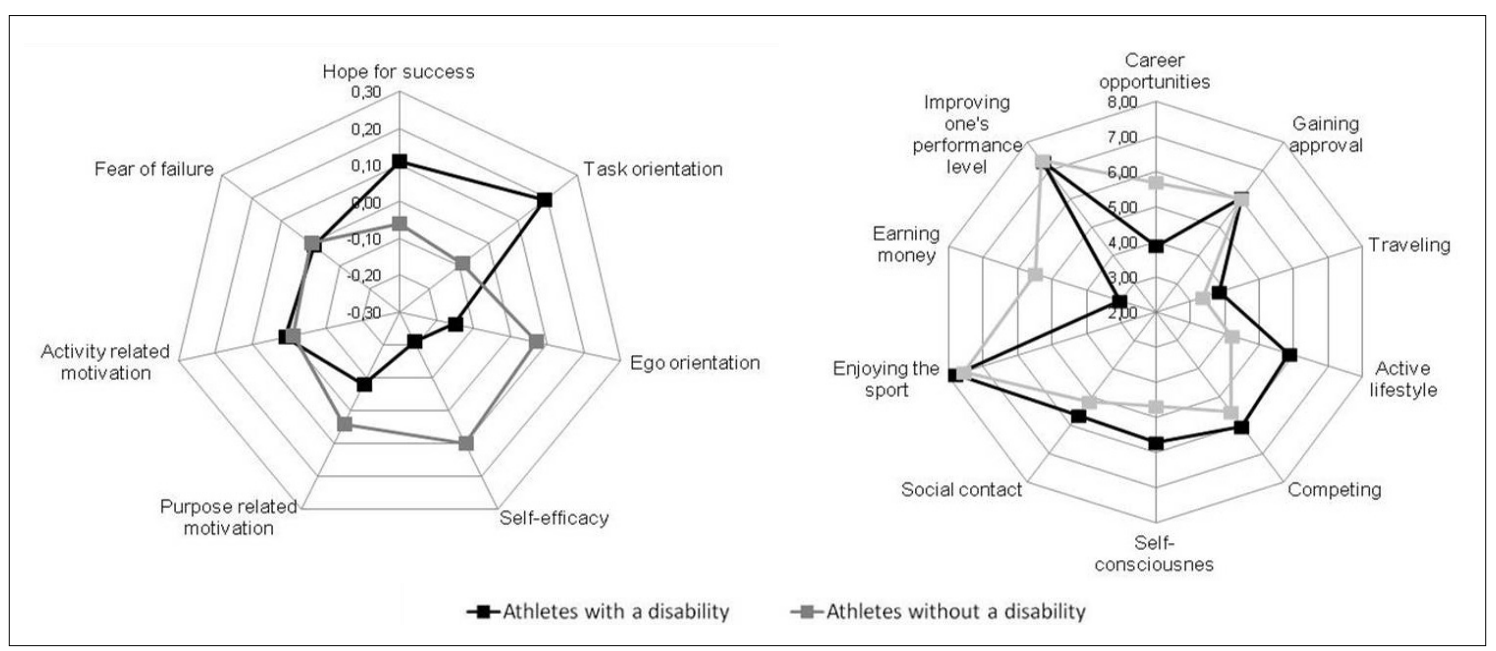

Figure 1. Top: Personal factors in the phase of mastery (z-scores); Bottom: Evaluation of situational incentives in the phase of mastery $(1=$ unimportant; $10=$ very important $)$ 
The multivariate analysis of ten motivational incentives from the ranking method(Figure 1, bottom and Table 3) also showed a significant difference between athletes with and without a disability. The effect of this result was large $\left(F_{10,205}=7.57 ; p<.001\right.$; $\left.\eta^{2}=.27\right)$. Furthermore, follow-up tests displayed a large difference concerning the variables "earning money" $\left(\eta^{2}=.18\right)$ and "having career opportunities" $\left(\eta^{2}=.09\right)$, which were less important among athletes with a disability. Otherwise, the incentives "leading an active lifestyle" $\left(\eta^{2}=.08\right)$ and "increasing selfconsciousness" $\left(\eta^{2}=.04\right)$ are significantly more important to athletes with a disability. By trend, but not meeting the level of significance, athletes with a disability considered the situational incentives "having social contact" $\left(\eta^{2}=.02\right)$ and "traveling around the world" $\left(\eta^{2}=.01\right)$ to be more important.

Table 3. Personal factors and situational incentives in the course of a career $(M \pm S)$ and multi- and univariate results of group differences between athletes with and without a disability in the mastery phase (controlled for gender and age)

\begin{tabular}{|c|c|c|c|c|c|c|c|c|c|}
\hline \multirow[b]{2}{*}{ Dependent variables } & \multicolumn{2}{|c|}{ Initiation } & \multicolumn{2}{|c|}{ Development } & \multicolumn{2}{|c|}{ Mastery } & \multicolumn{3}{|c|}{$\begin{array}{l}\text { Group differences in } \\
\text { the mastery phase }\end{array}$} \\
\hline & with & without & with & without & with & without & $F_{1,215}$ & p & $\eta^{2}$ \\
\hline \multicolumn{10}{|l|}{ Personal factors $\left(\mathrm{F}_{7,209}=2.56 ; \mathrm{p}=.015 ; \eta^{2}=.08\right)$} \\
\hline Hope for success $(\alpha=.74 / .80 / .84)^{\mathrm{a}}$ & $2.05 \pm .55$ & $2.02 \pm .55$ & $2.31 \pm .59$ & $2.18 \pm .55$ & $2.44 \pm .60$ & $2.34 \pm .53$ & 1.29 & .258 & .01 \\
\hline Fear of failure $(\alpha=.83 / .86 / .86)^{\mathrm{a}}$ & $0.87 \pm .59$ & $0.90 \pm .65$ & $0.85 \pm .69$ & $0.92 \pm .69$ & $0.79 \pm .73$ & $0.79 \pm .60$ & 0.00 & .980 & .00 \\
\hline Task orientation $(\alpha=.76 / .80 / .84)^{\mathrm{a}}$ & $2.30 \pm .51$ & $2.16 \pm .47$ & $2.37 \pm .51$ & $2.23 \pm .49$ & $2.43 \pm .58$ & $2.28 \pm .53$ & 5.95 & .016 & .03 \\
\hline Ego orientation $(\alpha=.85 / .88 / .90)^{\mathrm{a}}$ & $1.76 \pm .62$ & $1.89 \pm .69$ & $1.77 \pm .74$ & $1.90 \pm .73$ & $1.81 \pm .80$ & $2.00 \pm .78$ & 2.69 & .102 & .01 \\
\hline Activity-related motivation $(\alpha=.65 / .69 / .74)^{\mathrm{a}}$ & $3.09 \pm .87$ & $3.01 \pm .76$ & $3.07 \pm .94$ & $3.00 \pm .76$ & $2.96 \pm .98$ & $2.94 \pm .85$ & 0.10 & .753 & .00 \\
\hline Purpose-related motivation $(\alpha=.67 / .64 / .70)^{\mathrm{a}}$ & $3.07 \pm .75$ & $2.90 \pm .84$ & $3.20 \pm .75$ & $3.14 \pm .72$ & $3.30 \pm .80$ & $3.39 \pm .78$ & 0.64 & .423 & .00 \\
\hline Self-efficacy $(\alpha=.85 / .85 / .88)^{\mathrm{a}}$ & $1.97 \pm .61$ & $2.10 \pm .61$ & $2.06 \pm .62$ & $2.20 \pm .56$ & $2.15 \pm .68$ & $2.35 \pm .60$ & 2.83 & .094 & .01 \\
\hline \multicolumn{10}{|l|}{ Situational incentives $\left(\mathrm{F}_{10,205}=7.57 ; \mathrm{p}<.001 ; \eta^{2}=.27\right)$} \\
\hline Enjoying the sport & & & & & $7.79 \pm 2.65$ & $7.55 \pm 2.70$ & 0.68 & .411 & .00 \\
\hline Improving one's performance level & & & & & $7.29 \pm 2.35$ & $7.34 \pm 2.47$ & 0.05 & .823 & .00 \\
\hline Gaining approval & & & & & $6.01 \pm 2.49$ & $5.99 \pm 2.56$ & 0.97 & .325 & .01 \\
\hline Having career opportunities & & & & & $3.88 \pm 2.49$ & $5.69 \pm 2.99$ & 0.51 & .475 & .00 \\
\hline Leading an active lifestyle & & & & & $5.86 \pm 2.51$ & $4.20 \pm 2.80$ & 17.87 & $<.001$ & .08 \\
\hline Increasing self-consciousness & & & & & $5.72 \pm 2.34$ & $4.68 \pm 2.21$ & 9.46 & .002 & .04 \\
\hline Traveling around the world & & & & & $3.84 \pm 2.34$ & $3.36 \pm 2.34$ & 3.31 & .070 & .02 \\
\hline Competing with others & & & & & $6.04 \pm 2.53$ & $5.51 \pm 2.46$ & 21.45 & $<.001$ & .09 \\
\hline Having social contact & & & & & $5.64 \pm 2.69$ & $5.15 \pm 2.50$ & 2.91 & .089 & .01 \\
\hline Earning money & & & & & $3.04 \pm 2.60$ & $5.50 \pm 2.96$ & 48.16 & $<.001$ & .18 \\
\hline
\end{tabular}

a Internal consistency of the psychometric tests in the three career phases (initiation / development / mastery)

\section{Development of personal factors during elite sports careers (question 3)}

Analysis of interaction between the developmental and group factor only became significant for purpose-related motivation $\left(\eta^{2}=.02\right)$. This was caused by an increase from initiation $(\mathrm{M}=2.90)$ to mastery phase $(\mathrm{M}=3.39)$ within the group of athletes with a disability. The development of the remaining personal factors was similar for both groups, as the interaction effects failed to reach the significance level (at least $p>$.368). As a consequence (and nearly in accordance with the results from the second problem statement), the differentiation between athletes with and without a disability resulted in significant group effects for task orientation and self-efficacy. Both effects must be interpreted as small $\left(\eta^{2}=.03\right.$ and $\eta^{2}=.02$ ) (Figure 2 and Table 4). 

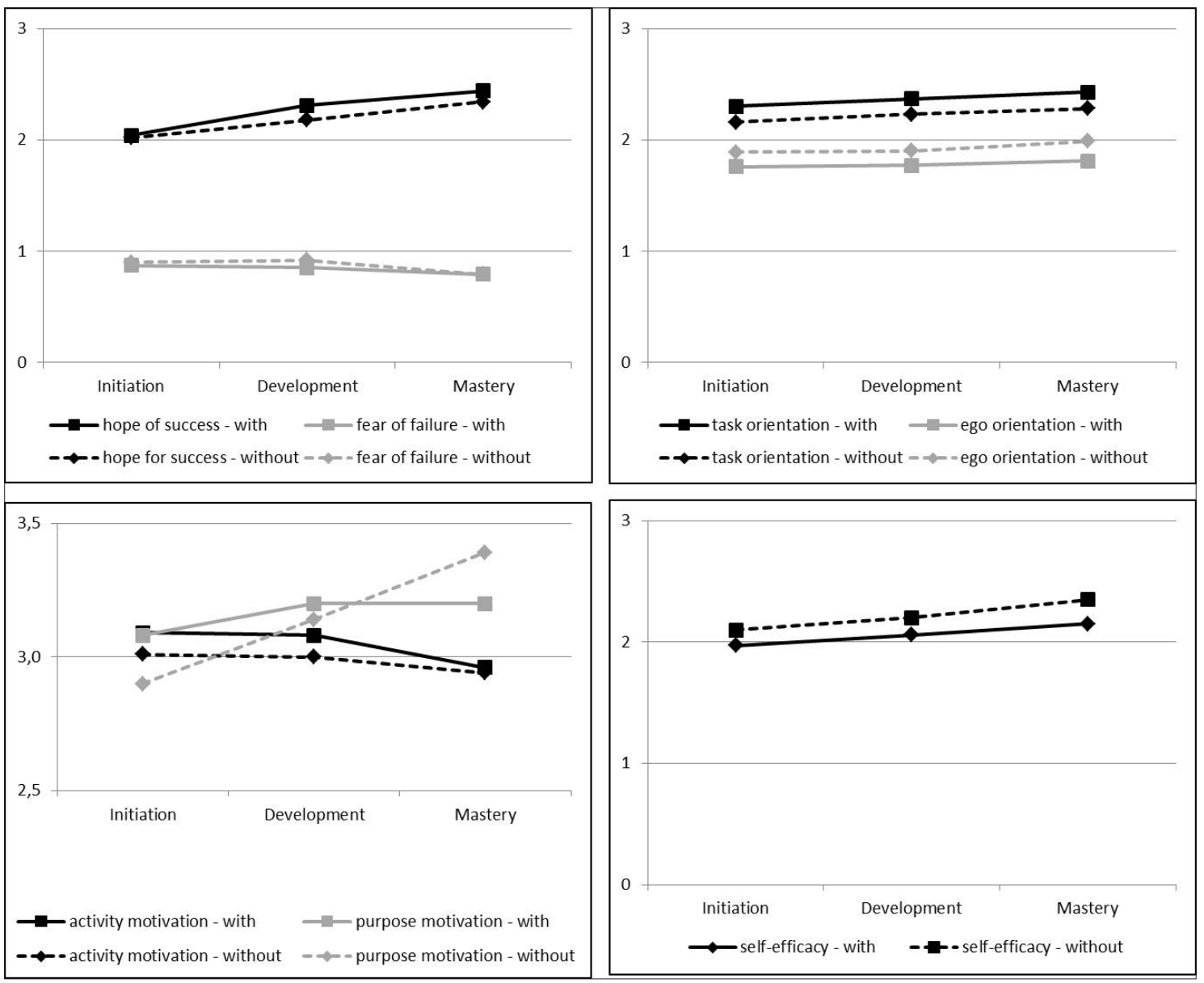

Figure 2. Development of personal factors in the course of a career for athletes with and without a disability (the exact descriptive values may be retrieved from Table 3) 
Kämpfe, Höner et al.

Table 4. Development of personal factors during elite sports careers (Repeated Measures ANOVAs controlled for gender and age)

\begin{tabular}{|c|c|c|c|c|}
\hline Personal factors & $\mathbf{F}$ & df & $\mathbf{p}$ & $\eta^{2}$ \\
\hline \multicolumn{5}{|l|}{ Hope for success } \\
\hline Developmental factor & 48.14 & $412.87,1.89$ & $<.001$ & .18 \\
\hline Group factor & 2.20 & 219,1 & .140 & .01 \\
\hline Interaction factor & 0.99 & $412.87,1.89$ & .368 & .01 \\
\hline \multicolumn{5}{|l|}{ Fear of failure } \\
\hline Developmental factor & 3.21 & 436,2 & .041 & .02 \\
\hline Group factor & 0.19 & 218,1 & .664 & .00 \\
\hline Interaction factor & 0.16 & 436,2 & .856 & .00 \\
\hline \multicolumn{5}{|l|}{ Task orientation } \\
\hline Developmental factor & 9.01 & $375.78,1.72$ & $<.001$ & .04 \\
\hline Group factor & 5.72 & 219,1 & .018 & .03 \\
\hline Interaction factor & 0.21 & $375.78,1.72$ & .967 & .00 \\
\hline \multicolumn{5}{|l|}{ Ego orientation } \\
\hline Developmental factor & 3.14 & $411.16,1.88$ & .047 & .01 \\
\hline Group factor & 1.92 & 219,1 & .167 & .01 \\
\hline Interaction factor & 0.58 & $411.16,1.88$ & .563 & .00 \\
\hline \multicolumn{5}{|l|}{ Activity-related motivation } \\
\hline Developmental factor & 4.36 & $375.80,1.75$ & .017 & .02 \\
\hline Group factor & 0.27 & 215,1 & .604 & .00 \\
\hline Interaction factor & 0.19 & $375.80,1.75$ & .798 & .00 \\
\hline \multicolumn{5}{|l|}{ Purpose-related motivation } \\
\hline Developmental factor & 28.72 & $360.81,1,71$ & $<.001$ & .12 \\
\hline Group factor & 0.18 & 214,1 & .670 & .00 \\
\hline Interaction factor & 4.10 & $360.81,1.71$ & .023 & .02 \\
\hline \multicolumn{5}{|l|}{ Self-efficacy } \\
\hline Developmental factor & 14.61 & $351.87,1.60$ & $<.001$ & .06 \\
\hline Group factor & 3.95 & 220,1 & .048 & .02 \\
\hline Interaction factor & 0.70 & $351.87,1.60$ & .496 & .00 \\
\hline
\end{tabular}

Concerning the developmental factor, the analysis reveals that hope for success, task orientation, ego orientation, purpose-related motivation and self-efficacy increased during the career phases. Meanwhile, fear of failure and activity-related motivation decreased (for descriptive data see Table 3). The development of hope for success can be classified as large $\left(\eta^{2}=.18\right)$, whereas purpose-related motivation and self-efficacy displayed a medium developmental effect $\left(\eta^{2}=.12\right.$ and $\left.\eta^{2}=.06\right)$. Fear of failure $\left(\eta^{2}=.02\right)$, task orientation $\left(\eta^{2}=.04\right)$, ego orientation $\left(\eta^{2}=.01\right)$ and activity-related motivation $\left(\eta^{2}=.02\right)$ showed rather small developmental effects. 


\section{DISCUSSION}

For several years, elite athletes have benefitted from understanding of psychological factors and have used that knowledge to enhance their performance. There is a strong need to provide equivalent knowledge for the growing field of elite disability sports. At present, empirical findings regarding the achievement motivation of athletes with a disability are quite rudimentary as psychological studies have mainly focused on monotheoretical approaches and have not considered developmental aspects. To reduce this deficit in the literature, we used an action-theoretical (Nitsch, 1985) and lifespan developmental perspective (Baltes et al., 2006) for our comparative study. Focusing on elite athletes with and without a disability, we conceptualized achievement motivation as a multidimensional and possibly multidirectional construct.

With the results of the first problem statement, the spectrum of motivational incentives was demonstrated. Elite athletes from disability sports engaged in their sport to experience enjoyment and to improve their athletic level, whereas material incentives such as career opportunities, traveling and earning money proved, at best, to be only a minimal incentive. The results are consistent with other studies analyzing German disability sports, where professionalism and commercialization seem to be less advanced compared to countries such as the USA or the UK (Scheid, Rank \& Kuckuck, 2003). Rather, the results of our study resemble the empirical findings from China (Chen, Wang, Jin \& Lau, 2007) and Norway (Pensgaard, Roberts \& Ursin, 1999); further generalization of these results appears to be difficult due to diverging states of commercialization in elite disability sports. Results were replicated by using alternative methods (Likert-scale and open-ended questions) and therefore the validity of the applied ranking method was satisfying. Only the motivational incentive "team spirit", which was mentioned most frequently in the open-ended method, was not addressed within the ranking method or within the Likert-based analysis. This incentive should be included in further empirical studies.

The results of the second problem statement showed that in the current phase of mastery, athletes with a disability differed significantly from athletes without a disability with respect to personal factors (medium effect $\eta^{2}=.08$ ) and even more so with respect to their perception of motivational incentives (large effect $\eta^{2}=.27$ ). The difference regarding personal factors can be predominantly attributed to different goal orientations as well as to a lower self-efficacy among athletes with a disability. The results for goal orientation confirm other empirical findings that claim athletes with a disability to be generally more task than ego orientated (e. g. Kemper \& Teipel, 2007; Skordilis et al., 2001). Furthermore, athletes with a disability demonstrated a significantly higher task orientation compared to athletes without a disability. However, the results regarding ego orientation of elite athletes displayed an inverse trend. This phenomenon can be interpreted as evidence of increased pressure on personal competition within elite sports. The ego-oriented facet of self-competence ("I want to be better than other athletes"), as compared to the task-oriented facet ("I want to perform my very best at this task"), receives more importance among athletes without a disability. Working with athletes from disability sports, these results can be seen as a means to motivate these athletes by focusing explicitly on task-oriented challenges and on ways to strengthen their self-efficacy by including practice situations that promote personal competence. With respect to the other personal factors, no significant group differences were found in this study. According to these results, it can be concluded that psychological consultations of athletes from disability sports can principally rely on existing diagnostics and standard values developed for athletes without a disability (e.g., the Sport Psychology Internet Service of the German Federal Institute of Sport Science, Wenhold et al., 2008).

Compared with the personal factors, motivational incentives differed significantly more between the two subsamples. Financial incentives and career opportunities were significantly less important to athletes with a 
disability, whereas enhancing self-consciousness and leading an active lifestyle were considered to be more essential. Enjoying the sport and improving one's performance level were the most important incentives for both groups. These results are consistent with empirical findings of Perrault and Vallerand (2007), who did not observe any differences between Canadian wheelchair basketball players with and without a disability regarding the dominating influence of intrinsic over extrinsic motivations.

With the third problem statement, the focus was placed on group differences concerning the development of personal factors in the course of a sports career, which was conceptualized into the three phases of initiation, development and mastery (Salmela, 1994; Wylleman \& Reints, 2010). A similar development for nearly all personal factors was evident for athletes of both subsamples. Only the purpose-related motivation displayed a stronger ascent among athletes with a disability. This finding is consistent with the results from the incentive ranking method, where athletes with a disability considered purpose-related incentives, such as money or career opportunities, to be less important than did athletes without a disability. Against the background of a proceeding, but comparably lower level of professionalization of a disability sport, these findings are quite plausible. We need to interpret this finding carefully and qualify it by considering the comparatively low internal consistency of purpose-related motivation in both retrospective phases $(<.70$; see section on dependent measures and table 3 ). However, since we did not focus on differences between individuals but on groups of athletes, these consistencies are still acceptable (Lienert \& Raatz, 1998, p. 14).

Further results within the third problem statement confirmed our conceptualization of achievement motivation being a multidimensional and, to some extent, multidirectional developing construct. All personal factors developed significantly during the course of a career. While fear of failure as well as activity-related motivation decreased, the perception of competence (self-efficacy) and both goal orientations (task and ego) increased over time. The largest increase was found in the disposition of hope for success. Likewise other elite athletes, athletes from disability sports can be characterized as highly success, confidence and task oriented in the beginning of their careers and even more so during the phase of mastery. Even though this study does not offer prospective longitudinal data, it seems plausible that hope for success displays an important precondition of athletic achievement. If an athlete with a disability has low hope for success, sport psychological interventions should focus on increasing this disposition so as to optimize the athletic achievement with respect to the conditions for talent or performance development.

As in any empirical study, the results of this research must be interpreted against the background of the methodological approach employed - in this case, against the retrospective survey method as well as the choice of sampling. Since retrospective surveys are always subject to recall bias, this method has been discussed intensively regarding the reliability and validity of the data (e.g., in the expertise research Baker, Côté, \& Abernethy, 2003). Based upon the fundamental works of Côté, Ericsson and Law (2005), the retrospective survey method has been well established for analyzing the developmental processes of elite athletes. Consequently, this method has been successfully used in numerous studies focusing on different sports such as rhythmic gymnastics, golf and team ball sports (Baker, Côté \& Abernethy, 2003; Hayman, Polman, Taylor, Hemmings \& Borkoles, 2011; Law, Côté \& Ericsson, 2007) and is considered to be an appropriate method for investigating career phases in the field of disability sports. Whereas these studies primarily refer to data such as frequency of practice, the retrospective analyses of personal factors may be subject to slightly greater methodical concern. However, the fact that we did not analyze absolute values but contrasted two different subsamples may reduce the methodical constraints of retrospection. Even when assuming a certain degree of recall bias, this phenomenon would concern both subsamples. Therefore, empirical findings from 
the comparative analyses still endure. The gold standard, a prospective longitudinal study, was not realizable due to economic (perennial study design) as well as practical reasons: Drawing an adequate sample of future elite athletes in the phase of initiation is quite difficult, especially in elite disability sports since there is no sophisticated talent development program in Germany and careers do not follow typical patterns known from elite sports. Often, athletes enter elite disability sports comparatively late in life and their inclusion appears to be more or less piecemeal. Therefore, we also need to consider that career phases as postulated by Salmela (1994) may differ between the two subsamples in terms of age. Especially those athletes who acquired their disability later in life may have passed through the same phases as compared to athletes without a disability - but certainly at an older age.

Furthermore, direct quantitative survey methods, as used in this study, generally measure explicit motives. To detect implicit motives, which are also important for behavioral control, projective methods are suggested (Brunstein, 2008) but had to be neglected in this study due to economic reasons. With respect to practical aspects of sports psychology, one must consider that in single case diagnostics, projective methods can reasonably complement a direct and quantitative method.

In terms of sampling, most studies dealing with disability sports focus on a single discipline (e.g., Martin et al., 1995; Martin, 2008). In our study, the goal was to obtain an overview regarding disability sports in general. To obtain a representative sample of German disability sports, we deliberately focused on a broad spectrum of disciplines (including both individual and team sports) and on physically impaired as well as sensory impaired athletes.

To summarize, theoretical specifications as well as empirical findings clarify that achievement motivation is a complex construct that includes several facets and requires sophisticated analysis. Further research in this field should focus on possible parameters causing the developmental trends demonstrated herein. Additionally, interventions promoting the discussed facets of achievement motivation must be developed and evaluated. This necessity persists particularly in the field of elite disability sports, whereupon existing knowledge from elite sports may be transferred.

\section{Perspective}

This research extends the rudimental knowledge concerning motivational aspects in elite disability sports. The theoretical analysis and the empirical study provide new implications on how to arrange training processes from a motivational point of view. For example, situations focusing explicitly on task-oriented challenges as well as situations promoting personal competence should be included regularly when practicing with elite athletes with a disability.

Furthermore, this research proves the feasibility of applying well elaborated psychological diagnostics from elite sports to elite disability sports. This may promote the utilization of psychological consultations - which is almost mandatory for elite athletes without a disability - also for athletes with a disability in order to optimize individual performance.

\section{REFERENCES}

Ashford, B., Biddle, S. \& Goudas, M. (1993). Participation in community sports centres: Motives and predictors of enjoyment. Journal of Sports Science, 11 (3), 249-256. doi: 10.1080/02640419308729992

Atkinson, J. (1957). Motivational determinants of risk taking behaviour. Psychological Review, 64 (6), 359-372.

Baker, J., Côté, J. \& Abernethy, B. (2003). Sportspecific practice and the development of expert decision-making in team ball sports. Journal of Applied Sport Psychology, 15 (1), 12-25. doi: 10.1080/10413200305400

Baltes, P. B., Lindenberger, U. \& Staudinger, U. M. (2006). Lifespan Theory in Developmental Psychology. In W. Damon \& R. M. Lerner (Eds.), Handbook of Child Psychology (pp. 569-664). Hoboken, New Jersey: Wiley.

Bandura, A. (1997). Self-efficacy: The exercise of 
control. New York: Freeman.

Biddle, S. J. H., Wang, J., Kavussanu, M. \& Spray, C. (2003). Correlates of achievement goal orientations in physical activity: A systematic review of research. European Journal of Sports Science, 3 (5), 1-19. doi: 10.1080/17461390300073504

Brunstein, J. C. (2008). Implicit and explicit motives. In J. Heckhausen \& H. Heckhausen (Eds.), Motivation and action (pp. 227-246). Cambridge: University Press. doi: 10.1017/ CBO9780511499821

Brunstein, J. \& Heckhausen, H. (2008). Achievement motivation. In J. Heckhausen \& H. Heckhausen (Eds.), Motivation and action (pp. 137-183). Cambridge: University Press. doi: 10.1017/CBO9780511499821

Chen, S. H., Wang, J., Jin, M., \& Lau, K. O. (2007). Motivation of sport participation in elite athletes with physical disabilities in Mainland China. Asian Journal of Exercise \& Sports Science, 4 (1), 63-67.

Cohen, J. (1988). Statistical power analysis for the behavior sciences (2nd ed.). Hillsdale: Lawrence Erlbaum Associates.

Côté, J., Baker, J., \& Abernethy, B. (2003). From play to practice: Adevelopmental framework for the acquisition of expertise in team sports. In J. Starkes \& K. A. Ericsson (Eds.) Expert performance in sports: Advances in research on sport expertise (pp. 89-110). Champaign, IL: Human Kinetics.

Côté, J., Ericsson, K., \& Law, M. (2005). Tracing the development of elite athletes using retrospective interview methods: A proposed interview and validation procedure for reported information. Journal of Applied Sport Psychology, 17 (1), 1-19. doi: 10.1080/10413200590907531

Desharnais, R., Bouillon, J. \& Godin, G. (1986). Self-efficacy and outcome expectations determinants of exercise adherence. Psychological Reports, 59 (3), 1155-1159.

Duda, J. L. (1992). Motivation in sport settings: A goal perspective approach. In G. C. Roberts (ed.), Motivation and sport and exercise (pp. 57-91). Champaign: Human Kinetics Publishers.

Duda, J. L. (2007). Motivation in sport: A goal perspective approach. In D. Smith \& M. Bar-Eli (Eds.), Essential readings in sport and exercise (pp. 78-93). Champaign: Human Kinetics.

Dzewaltowski, D. A., Noble, J. M. \& Shaw, J. M. (1990). Physical activity participation: Social cognitive theory versus the theories of reasoned action and planned behaviour. Journal of Sport and Exercise Psychology, 12 (4), 388-405.

Ericsson, K. A., Krampe, R. T. \& Tesch-Römer, C. (1993). The role of deliberate practice in the acquisition of expert performance. Psychological Review, 100 (3), 363-406.

Feltz, D. L. \& Lirgg, C. D. (2001). Self-efficacy beliefs of athletes, teams, and coaches. In R. N. Singer, H. A. Hausenblas \& C. Janelle (Eds.), Handbook of Sport Psychology (pp. 340-361) ( $2^{\text {nd }} E d$.). New York: Wiley \& Sons.

Frick, B. \& Prinz, J. (2007). Pay and performance in professional road running: The case of city marathons. International Journal of Sport Finance, 2 (1), 25-35.

Fuchs, R. \& Schwarzer, R. (1994). Selbstwirksamkeit zur sportlichen Aktivität: Reliabilität und Validität eines neuen Messinstruments. [Self-efficacy of sportive activity: Reliability and validity of a new measure]. Zeitschrift für Differenzielle und Diagnostische Psychologie, 15 (3), 141-154.

Gill, D. L. \& Deeter, T. E. (1988). Development of the sport orientation questionnaire. Research Quarterly for Exercise and Sport, 59 (3), 191-202.

Hayman, R., Polman, R., Taylor, J., Hemmings, B. \& Borkoles, E. (2011). Development of elite adolescent golfers. Talent Development \& Excellence, 3 (2), 249-261.

Kämpfe,A.(2009).HomoSportivus Oeconomicus. Intrinsische und extrinsische Motivation im Verlauf von Spitzensportkarrieren. [Intrinsic and extrinsic motivation during elite sport careers]. Köln: Strauß.

Kemper, R., \& Teipel, D. (2007). Comparison of goal-setting and identity of nonhandicapped and handicapped high-level athletes. In D. Teipel, R. Kemper, \& Y. Okade (Eds.), Topics of social and behavioral science in 
sport (pp. 235-243). Köln: Strauß.

Law, M., Côté, J., \& Ericsson, K. (2007). Characteristics of expert development in rhythmic gymnastics: A retrospective study. International Journal of Exercise and Sport Psychology, 5 (1), 82-103. doi: 10.1080/1612197X.2008.9671814

Lewin, K. (1936). Principles of topological psychology. New York: McGraw-Hill.

Lienert, G. A. \& Raatz, U. (1998). Testaufbau und Testanalyse [Test setting and test analysis]. Weinheim: Belz.

Martin, J. J. (2002). Training and performance self-efficacy, affect, and performance in wheelchair road racers. The Sport Psychologist, 16 (4), 384-395.

Martin, J. J. (2008). Multidimensional selfefficacy and affect in wheelchair basketball players. Adapted Physical Activity Quarterly, 25 (4), 275-288.

Martin, J. J., Adams-Mushett, C. \& Smith, K. (1995). Athletic identity and sport orientation of adolescent swimmers with disabilities. Adapted Physical Activity Quarterly, 12 (2), 113-123.

McClelland, D. C. (1953). The achievement motive. New York: Appleton-CenturyCrofts.

Moritz, S. E., Feltz, D. L., Fahrbach, K. R., \& Mack, D. E. (2000). The relationship of selfefficacy measures to sport performance: A meta-analytic review. Research Quarterly for Exercise and Sport, 71 (3), 280-294.

Murray, H.A. (1938). Explorations in personality. New York: Oxford University Press.

Nicholls, J. G. (1984). Conceptions of ability and achievement motivation. In R. Ames \& C. Ames (Eds.), Research on Motivation in Education (pp. 39-73). New York: Acad. Press.

Nitsch, J. R. (1985). The action-theoretical perspective. International Review for Sociology of Sport, 20 (4), 263-282.

Pensgaard, A. M., Roberts, G. C. \& Ursin, H. (1999). Motivational factors and coping strategies of Norwegian Paralympic and Olympic winter sport athletes. Adapted
Physical Activity Quarterly, 16 (3), 238-250.

Perreault, S. \& Vallerand, R. J. (2007). A test of Self-Determination-Theory with wheelchair basketball players with and without disability. Adapted Physical Activity Quarterly, 24 (4), 305-316.

Rethorst, S. \& Wehrmann, R. (1998). Der TEOSQ-D zur Messung der Zielorientierung im Sport. [The TEOSQ-D as a measure of goal orientations in sport]. In D. Teipel, R. Kemper \& D. Heinemann (Hrsg.), Sportpsychologische Diagnostik, Prognostik, Intervention (S. 57-63). Köln: bps.

Rheinberg, F. (1989). Zweck und Tätigkeit. Motivationspsychologische Analysen zur Handlungsveranlassung [Purpose and action. Motivation psychological analyses regarding the cause of action]. Göttingen: Hogrefe.

Rheinberg, F. (2008). Intrinsic motivation and flow. In J. Heckhausen \& H. Heckhausen (Eds.), Motivation and action (pp. 323348). Cambridge: University Press. doi: 10.1017/CBO9780511499821.014

Salmela, J. H. (1994). Phases and transitions across sport careers. In D. Hackfort (Ed.), Psycho-social issues and interventions in elite sports (pp.11-28). Frankfurt: Lang.

Scheid, V. Rank, M. \& Kuckuck, R. (2003). Behindertenleistungssport. [Elite disability sports]. Aachen: Meyer \& Meyer.

Skordilis, E. K., Koutsouki, D., Asonitou, K., Evans, E., Jensen, B. \& Wall, K. (2001). Sport orientations and goal perspectives of wheelchair athletes. Adapted Physical Activity Quarterly, 18 (3), 304-315.

Wenhold, F., Elbe, A.-M. \& Beckmann, J. (2008). AMS-Sport Kurzversion: Allgemeiner Fragebogen zum Leistungsmotiv im Sport. [AMS-Sports short version: A general questionnaire to measure the achievement motive in sports]. Retrieved from http:// www.bisp.de.

White, S. A. \& Duda, J. L. (1993). Dimensions of goals and beliefs among adolescent athletes with physical disabilities. Adapted Physical Activity Quarterly, 10 (2), 125-136.

Willimczik, K. \& Kronsbein, A. (2005). 
Kämpfe, Höner et al.

Leistungsmotivation im Verlauf von Spitzensportkarrieren. [Achievement motivation in elite sports careers]. Leistungssport, 35 (5), 4-10.

Wylleman, P., \& Reints, A. (2010). A lifespan perspective on the career of talented and elite athletes: Perspectives on high-intensity sports. Scandinavian Journal of Medicine \& Science in Sports, 20 (2), 88-94. doi: 10.1111/j.1600-0838.2010.01194.x 